Revue d'histoire du XIXe siècle

Société d'histoire de la révolution de 1848 et des

révolutions du XIXe siècle

$53 \mid 2016$

Mobilités, savoir-faire et innovations

\title{
Quentin DELUERMOZ et Anthony GLINOER [dir.], L'insurrection entre histoire et littérature (1789-1914)
}

Paris, Publications de la Sorbonne, 2015

\section{Thomas Bouchet}

\author{
CpenEdition \\ Journals \\ Édition électronique \\ URL : http://journals.openedition.org/rh19/5141 \\ DOI : 10.4000/rh19.5141 \\ ISSN : $1777-5329$ \\ Éditeur \\ La Société de 1848 \\ Édition imprimée \\ Date de publication : 1 décembre 2016 \\ Pagination : 202-203 \\ ISSN : 1265-1354 \\ Référence électronique \\ Thomas Bouchet, « Quentin DELUERMOZ et Anthony GLINOER [dir.], L'insurrection entre histoire et \\ littérature (1789-1914) », Revue d'histoire du XIXe siècle [En ligne], 53 | 2016, mis en ligne le 21 février \\ 2017, consulté le 25 septembre 2020. URL : http://journals.openedition.org/rh19/5141 ; DOI : https:// \\ doi.org/10.4000/rh19.5141
}

Ce document a été généré automatiquement le 25 septembre 2020.

Tous droits réservés 


\section{Quentin DELUERMOZ et Anthony GLINOER [dir.], L'insurrection entre histoire et littérature (1789-1914)}

Paris, Publications de la Sorbonne, 2015

\section{Thomas Bouchet}

\section{RÉFÉRENCE}

Quentin DELUERMOZ et Anthony GLINOER [dir.], L'insurrection entre histoire et littérature (1789-1914), Paris, Publications de la Sorbonne, 2015, 154 p., $22 €$.

1 À quoi rime l'écriture de l'insurrection ? Les deux coordonnateurs du volume, épaulés par huit contributeurs, remettent sur le métier cette interrogation qui a déjà fait couler beaucoup d'encre. À eux tous ils mettent en lumière les enjeux les plus importants de la question. L'introduction générale, qui propose de très nombreux renvois bibliographiques, est à cet égard un modèle du genre. Puis chacune des études apporte des touches supplémentaires au tableau. L'équipe est composée à parts égales de littéraires et d'historiens. Les uns et les autres mobilisent leurs manières habituelles de faire mais ils ouvrent aussi des perspectives de recherche qui dépassent les limites des champs disciplinaires convoqués. L'axe général fixé pour la réflexion en témoigne : il s'agit de mieux comprendre «ce que l'insurrection, temps d'ouverture des possibles, espérés ou craints, fait à l'écriture et à la littérature ; ce que la littérature, ses auteurs, ses topiques, fait dans le temps insurrectionnel $»\left(4^{\mathrm{e}}\right.$ de couverture).

2 Toutes les études rassemblées portent sur la France, et plus précisément sur Paris. Elles explorent les diverses modalités de l'insurrection écrite au sens strict sans élargir la perspective à l'insurrection dessinée et peinte, à l'insurrection chantée. Elles permettent d'arpenter plusieurs séquences d'un long XIX ${ }^{\mathrm{e}}$ siècle. Certaines, telle la séquence 1827-1834, restent dans l'ombre - mais c'est la loi du genre pour un recueil qui ne se veut ni exhaustif ni synthétique. Au total deux contributions portent sur la 
Révolution (Jean-Luc Chappey, Corinne Saminadayar-Perrin), quatre sur les années de Deuxième République (Sébastien Hallade, Laura O’Brien, Sarah Mombert, Anthony Glinoer), deux sur l'après-Commune (Stéphane Zékian, Laure Godineau). Parmi elles en voici deux, issues de l'univers des études littéraires - et donc en apparence quelque peu exotiques pour les historiens. Elles ne se ressemblent pas mais elles ont en commun une rigueur remarquable et une extrême précision, de grandes qualités de réflexion et d'exposition.

3 Dans "Le peuple souverain : le 20 juin 1792 (Michelet, Dumas) », Corinne Saminadayar-Perrin se penche sur deux modes d'écriture d'un même événement insurrectionnel. Elle décortique l'Histoire de la Révolution française et La Comtesse de Charny, deux livres publiés respectivement dans le sillage des journées de Juin 1848 et dans celui du coup d'État du 2 décembre 1851. Elle s'appuie notamment sur les scénarisations d'ensemble, le montage des récits et le système des personnages pour montrer comment les deux écrivains relèvent un défi majeur : « faire entendre la voix du peuple insurgé ". Il vaut à ce propos la peine de lire en parallèle l'étude que Sarah Mombert signe dans ce même volume sur Dumas et son journal Le Mois (1848-1850).

4 Stéphane Zékian livre quant à lui des pages extrêmement riches sur Louise Michel (« Roman, oralité, incorrection. Louise Michel et l'écriture de l'insurrection »); il fonde ses analyses sur trois romans méconnus - Les Microbes humains (1886), Le Monde nouveau (1888), Le Claque-dents (1890) - qu'il a édités avec Claude Rétat en 2013. La " bizarrerie formelle » de ces trois romans, loin de les disqualifier, fait d'eux des points d'accès privilégiés au travail subversif sur le langage auquel s'emploie Louise Michel ; Stéphane Zékian caractérise en détails l'ambition et aussi les limites de ce projet d'écriture de l'insurrection où l'« incorrection » est un maître-mot.

Alain Vaillant est l'auteur de la contribution qui conclut le volume et qui porte sur le siècle dans son ensemble. Il revient sur des questions abordées au fil de l'ouvrage et il propose quantité de pistes stimulantes. On pourra en retenir par exemple cette idée : malgré Les Misérables ou L'Éducation sentimentale, la poésie pourrait bien être plus apte que le roman à exprimer l'insurrection. Alain Vaillant invite à étudier avec attention toute une " littérature de l'interpellation, de la déclaration manifestaire, du combat, voire de l'invective ou, à l'inverse, de la déploration » (p. 144). Il insiste sur l'intérêt stratégique de la "poésie insurrectionnelle, qui est formellement inséparable de la violence politique qu'elle exprime et dont elle permet le défoulement, autant chez celui qui la dit que parmi son auditoire » (p. 147). À l'introduction du volume qui s'ouvre sur un poème de Rimbaud (" Les Forçats ») fait ainsi écho ce dernier chapitre qui s'achève sur une référence appuyée au même Rimbaud.

$6 \quad$ L'Insurrection entre histoire et littérature n'a qu'un défaut : son prix élevé. Pour le reste, ce livre stimule l'esprit, aiguise la curiosité, encourage à poursuivre les recherches. 